\title{
ALFRED FARAĞ, UN INQUIETO DRAMATURGO EGIPCIO CONTEMPORÁNEO: TRADUCCIÓN DE SU PIEZA EL INDIVIDUO (AL-ŠAJṢ)
}

\section{Pilar Lirola Delgado}

Son ya casi cincuenta años los que Alfred Farağ lleva consagrando su actividad creativa al teatro. Su pluma ha sido fecunda tanto en cuanto a la cantidad de trabajos que ha engendrado - ronda la treintena - como a la variedad de asuntos y técnicas manejadas; y el resultado de su labor ha sido calificado por la crítica árabe como de gran calidad artística. Ha cultivado también, aunque con menor profusión, el ensayo y la narrativa.

Nacido en 1929 en una pequeña aldea del norte de Egipto en el seno de una familia copta, Alfred Farağ pasó su niñez y juventud en Alejandría, licenciándose en 1949 en la Facultad de Letras de esta ciudad. Durante algunos años conjugó su trabajo de profesor de inglés en la enseñanza secundaria con sus contribuciones de crítica literaria a diferentes publicaciones seriadas. Sus años de formación y los inicios de su actividad profesional se desarrollaron en una etapa de tensiones y revueltas en el Egipto monárquico. Apoyó en principio el régimen republicano posterior al Golpe de Estado de los Oficiales Libres de 1952 por hacer en parte realidad los deseos nacionalistas del pueblo egipcio. En 1955 dejó la enseñanza para dedicarse a la creación literaria, contribuyendo desde entonces con sus artículos críticos sobre teatro y cine al joven periódico al-Ğumhüriyya, órgano de expresión del nuevo régimen. Inició también por esas fechas su carrera de autor dramático, colaborando además en la producción escrita de algunos guiones cinematográficos y televisivos. Y participó activamente en lo que se ha llamado «florecimiento del teatro egipcio» que tuvo lugar entre mediados de los años cincuenta y especialmente durante los años sesenta, etapa que coincide con la del gobierno de Ğamāl ${ }^{\mathrm{c}} \mathrm{Abd}$ al-Nāșir y que se encuadra dentro de una época de prosperidad en el campo de la cultura fomentada por el mismo gobierno ${ }^{1}$.

$\mathrm{Al}$ igual que otros intelectuales simpatizantes de la izquierda fue blanco de una de las purgas del joven gobierno republicano, estando encarcelado entre 1959 y 1963. Después de

1 En ello me centré en mi artículo "El teatro egipcio de los sesenta: Yūsuf Idrīs y Alfred Farağ. Dos itinerarios convergentes en favor de la Libertad y la Justicia". Miscelánea de Estudios Árabes y Hebraicos (Sección ÁrabeIslam), 48 (1999), 157-176. A su labor dramática también aludía en mi libro Aproximación al teatro egipcio moderno. Granada: Grupo de Investigación "Estudios Árabes Contemporáneos", Universidad de Granada, 1990, 72, 76, 82, 84-86, 109, 118. 
salir de prisión obtuvo algunos reconocimientos por parte del mismo régimen, ocupando entre 1967 y 1973 diferentes cargos importantes como funcionario del Ministerio de Cultura dirigidos a la promoción del género dramático, tanto en la capital como en las provincias.

En 1973, ante el clima de agitación por la insostenible situación generada, entre otras cosas, por la guerra de desgaste con Israel y las represalias que durante los primeros años de su mandato adoptó el gobierno de Anwar al-Sādāt contra los intelectuales que denunciaron tal circunstancia, decidió marcharse a Argelia, donde trabajó para la televisión y para el Ministerio de Educación, además de continuar con la composición dramática; de allí pasó a residir, seis años después, en Londres. Actualmente y desde mediados de los ochenta vive entre Londres y El Cairo. Desde 1995 escribe en el conocido periódico cairota al-Ahrām y es asesor de la Comisión de Teatro del Consejo Superior de Cultura. Asiste con relativa frecuencia a diferentes foros sobre el teatro en el mundo árabe, América y Europa².

La producción dramática de Alfred Farağ fue muy fértil durante los años sesenta y primeros de los setenta publicando y llevando a escena en El Cairo al menos una obra por año; después ha sido algo más pausada, pero también importante. Ha tenido y sigue teniendo una amplia difusión no sólo en su país sino en otros países árabes e, incluso, se han traducido y puesto en escena varias de sus obras en algunos países occidentales. Y ello quizá se deba a que, independientemente de la forma de expresión elegida en sus creaciones -realista, cómica, trágica, histórica o legendaria-, ha considerado el teatro esencialmente como una modalidad de diálogo, planteando materias que preocupan a la sociedad en general.

En la historia del teatro árabe han quedado inmortalizados varios de sus trabajos entre los que podemos destacar: El barbero de Bagdad (Hallāq Bagdād, 1963), comedia fantástica que, inspirada en relatos de Las mil y una noches y de al-Ğāhiz, gira en torno a ideas que siguen preocupando en la sociedad moderna -la verdad, la justicia, el amor y la democracia-; fue su primer gran éxito al representarse en 1964 en el Teatro Nacional y después fue llevada a otros escenarios árabes de Siria, Jordania, Iraq, Kuwait, además del de la Universidad de Varsovia; El Príncipe Sălim (al-Zīr Sălim, 1967), tragedia en la que hace una reelaboración de un romance popular sobre las guerras intertribales en la Arabia preislámica clamando por la justicia, representada en Túnez, Siria, Jordania, Libia e Iraq; 'Alī Găăh al-Tabrīzī y su seguidor Quffa ('Alī Ğanăh al-Tabrī̄īwa-tābicu-hu Quffa, 1968), comedia popular con buena dosis de imaginación elaborada igualmente a partir de varios cuentos de Las mil y una noches y en la que retoma el tema para él recurrente de la justicia social, que se ha visto, además en escenarios de Iraq, Kuwait, Sudán, Túnez, Siria y la República Federal Alemana; El fuego y el olivo (al-Nār wa-l-zaytūn, 1969), drama político sobre la cuestión palestina en su lucha contra el sionismo, representada también en la República Democrática Alemana, Iraq, Kuwait

\footnotetext{
${ }^{2}$ Alfred Farağ ha pasado varias veces por España, la última vez para tratar de su aportación al teatro en el Encuentro Internacional sobre el Autor Teatral y el Siglo XX, organizado por el Ministerio de Educación y Cultura y celebrado entre el 25 y el 27 de noviembre de 1998 en Madrid, intervención que se espera que sea publicada en las correspondientes Actas.
} 
y Siria; o Matrimonio en un acta de divorcio (Zawāğ calà waraq al-țalāq, 1972), comedia social que, recurriendo a la técnica pirandelliana del teatro dentro del teatro, expone la ruptura entre la clase burguesa y el pueblo, llevada a escena en Túnez, Inglaterra, Siria y Libia.

Es interesante mencionar que ha realizado tres adaptaciones de obras occidentales, proponiendo a su entender así un tipo de diálogo con Occidente con protagonistas y hechos desarrollados en un contexto árabe: El amor es un juego (al-Hubb licba, 1974), comedia social que toma su argumento de la obra de Marivaux Le jeu de l'amour et du hasard; Graciosos ricos y pobres (Agniy $\vec{a}$, fuqar $\vec{a}$, zurafă, 1975$)$, comedia musical también de contenido social basada en la Commedia dell'Arte siguiendo el estilo de la farsa de Benavente Los intereses creados; y Las aventuras de 'Atwa Abū Mațwa (Garamiyyāt 'Atẉa Abū Mața, 1993), adaptación de una ópera de Brecht.

Las obras de Alfred Farağ se siguen representando dentro y fuera de Egipto. Éste es el caso de El Individuo (al-Šajs s) $)^{3}$, escrita en 1989, estrenada en el II Festival Internacional de Teatro Experimental de El Cairo en el mismo año y, después, llevada a escena en la Universidad de Nueva York. Es una de sus varias piezas en un acto, así como una de las obras de la que el autor se siente más satisfecho. De carácter filosófico y existencial, plantea la frustración y la crisis que vive el hombre, atrapado por el tiempo y por el recuerdo. Presente y pasado, memoria individual y colectiva, cotidianidad, mito y ritual se combinan en la obra. El absurdo de la sociedad moderna, las presiones económicas, la soledad, la incomunicación o el despotismo y la inoperancia de aquellos que poseen el poder son algunos temas que salen a relucir ${ }^{4}$.

La mayor parte de sus obras están escritas en una lengua culta y elocuente que se adapta a los asuntos y ambientes tratados. No ha rechazado, sin embargo, el empleo de registros coloquiales en algunas piezas generalmente de corte social en las que parecía más indicado su uso, y así lo hizo en la obra que presentamos.

Su actividad literaria ha obtenido destacados galardones en el mundo árabe entre los que sobresalen: el Premio "Sultán "Uways" de 1992, concedido en los Emiratos Árabes y que es considerado el Nobel de las letras árabes; y el Premio de Valoración del Estado Egipcio de 1993. Entre las diversas distinciones honoríficas en certámenes de teatro merece destacarse el premio al mejor dramaturgo egipcio en 1999.

${ }^{3}$ En Alfred Farağ. Mu'allafāt Alfred Farağ. Vol. 11. El Cairo: al-Hay'a al-Mișriyya al-'Āmma li-1-Kitāb, 1990, $143-$ 180.

${ }^{4}$ Dina Amin ha hecho una lectura de la pieza en su artículo "Temporal and spatial re-construction through memory: a postmodernist perspective in Alfred Farag's play, al-Shakhs". Journal of Arabic Literature, XXIX, 3-4 (1998), 167 184. 


\section{Pieza experimental en cuadros}

\section{PERSONAJES}

\author{
EL INDIVIDUO \\ EL SEMEJANTE \\ El MÉdICO \\ DOS JÓVENES MUSCULOSOS \\ LA ENFERMERA \\ EL RICO
}

LA BAILARINA

EL PORTERO

EL CARTERo

El Policía

UN GORILA
El padre - El hijo

Es la viva estampa del Individuo

Con bata blanca

A veces son Enfermeros y siempre van juntos

Unas veces hace de Partera, otras se ocupa de sahumar

Se dedica a hablar de los placeres de la vida y siempre está con el narguile

\section{Con atuendo autóctono}

También Amanuense cuando se quita la gorra

Música de apertura. De pronto aparecen los personajes uno tras otro. Llevan pancartas en las que aparecen dibujados los signos $i-j-+---=-,-i j-\ll \ldots »-$ $x-$ : con los que marcan un baile expresionista. Golpes de mortero y desaparecen los carteles. Cortejo de celebración de un nacimientos. Los diez personajes se organizan en el cortejo. La Partera hace albórbolas. La Bailarina danza. El Rico mantiene en su mano el narguile. Los otros lanzan al aire un cedazo con garbanzos. Los dos Jóvenes sostienen un gran cedazo sobre el que está el Individuo en pañales; se los quita y se baja del cedazo. El Gorila, en la parte superior de la escena, se golpea el pecho y la imagen queda instantáneamente inmovilizada. Hay signos de estupor y miedo en los rostros de los personajes. Entretanto, se van apagando las luces, a la vez que van desapareciendo uno tras otro, empezando por el Gorila, hasta

\footnotetext{
${ }^{5}$ La palabra subưf hace referencia a la ceremonia que tiene lugar a los siete días del nacimiento de un bebé. Para la ocasión se preparan platos y bebidas especiales. Entre otras cosas, también se machaca sal en un mortero con el objeto de que el niño se acostumbre a escuchar sonidos fuertes, así como se reparte sal por la casa para preservarlo del mal

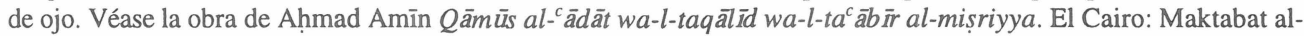
Nahda al-Mișriyya, s.d. $^{2}\left(1953^{\mathrm{l}}\right), 229$.
} 
que no queda en escena más que el Individuo. Los golpes de mortero van siendo más espaciados. El Individuo lleva la indumentaria del anciano padre.

EL INDIVIDUO: Es la una y no sé qué es lo que me ha traído aquí ni quién es esa gente. Tengo que ir a algún sitio y, por mucho que ande, me vuelvo a encontrar de nuevo aquí. Esto parece ser una imagen irreal. Ni tan siquiera recuerdo si ésa era la celebración de mi nacimiento o la de mi único hijo. Si fuera la de mi nacimiento, ¿cómo iba a tener una imagen de ella cuando no puedo recordarla ni acordarme de la gente que estaba allí? Y, si fuera la celebración de mi hijo, ¿cómo es que no me acuerdo del nombre de ninguno de ellos, ni en qué trabajan ni en calidad de qué estaban invitados? Y lo que más me asusta es que se me olvida todo, se me va la memoria. Yo iba a hacer lo que tenía que hacer. ¿Dónde? No me acuerdo. Tengo una cita a las doce en punto o quizá a las dos. ¿Con quién? No consigo recordar. Por más que trato de recordar, me ronda esa imagen en la que aparece esa gente, ese tropel. Pretenden recordarme algo, pero yo lo he olvidado. Me rondan como pedacitos de una foto rota que se recompone ante mí. Pienso en el porqué, el quién y el cuándo, pero no consigo recordar. ¿Y por qué precisamente esta imagen? Me persigue desde hace tiempo, como si fuera el espíritu del pasado, un espíritu del pasado que insiste en recordarme algo que yo he olvidado. Me hace volver hacia atrás cuando lo que queremos es ir hacia adelante. La imagen me devuelve hacia atrás. Pretende alterar mi trayectoria y hacerme volver atrás. Y yo tengo que ir a algún sitio y quiero avanzar hacia adelante. No sé por qué quiero recordar algo que no recuerdo; y siempre que lo recuerdo tengo prisa y estoy obsesionado con eso que tengo que hacer. Si el hombre está condenado a que su edad vaya avanzando, ¿por qué en su memoria tiene lugar la vuelta al pasado? Si todas sus miras están puestas en el futuro, ¿por qué lo distraen sus fantasías y le hacen volver hacia atrás? Yo, por naturaleza, soy olvidadizo. ¿Por qué mi memoria forja esa imagen? Y eso es algo que ocurre desde hace tiempo, algo inútil y sin sentido. No quiero volver sobre lo mismo otra vez; no quiero hacerlo, tengo prisa. He esperado mucho, y ya no hay tiempo. Pero, ¿por qué voy así vestido y a dónde voy? Lo he olvidado. Lo he olvidado. Lo he olvidado. Lo único que me queda es vacío, y el vacío es igual al principio que al final, y en el centro como un emblema está escrito «prohibido esperar». Pero, ¿cómo puede suceder esto? Llevo toda la vida esperando e hipotecando mi vida por ese día, y cuando llega ese día resulta que he olvidado qué es lo que estaba esperando. Es una desgracia que no puede menos que suscitar la risa. Es como si yo fuera un personaje de la tragedia griega; y la tragedia no es más que toda esta espera. Siendo niño esperé a hacerme mayor para poder librarme de las prohibiciones y disfrutar de la libertad de los mayores. En la escuela viví esperando el examen y el resultado del examen. Estuve esperando pasar de primero a segundo, y de segundo a tercero hasta que obtuve el bachillerato. Y seguí esperando a que la oficina gubernamental de empleo me colocara; después continué esperando a tener dos perras gordas para casarme y esperar a que mi mujer me trajera a mi único hijo, 
tras lo que esperé a educarlo y a que creciera hasta que consiguiera el bachillerato. Esperé entonces a que consiguiera un empleo para esperar dos perras gordas y que se casara. Toda mi vida hipotecada y perdida en el mar de la espera; y, de tanto esperar, he olvidado qué espero. Esperando obtener un nuevo ascenso, conseguí la escala cuarta, tercera y segunda; me jubilé y continué esperando que a mi hijo le saliera un contrato laboral en el extranjero con el fin de que me enviara dos perras gordas para ir al doctor a que me hiciera un chequeo y esperar el resultado de los análisis y de las radiografías. ¡Ya está! Me acabo de acordar. Tengo una cita con el doctor. Eso es lo que tenía que hacer a las dos y que había olvidado. La cita con el doctor.

\section{LAS DOS}

(En la clínica del Médico hay un rótulo con su título que custodian dos Enfermeros musculosos. La Enfermera en el despacho se queda mirando al Individuo con los ojos muy abiertos mientras sostiene el auricular del teléfono en el oído. Los otros personajes, a excepción del Gorila, son enfermos que esperan inmóviles. Detrás del rótulo está el Médico con su estetoscopio en el pecho del enfermo, el Semejante del Individuo. Ambos están también inmóviles.)

EL INDIVIDUO: La verdad es que no me quejo en concreto del dolor de corazón, ni del estómago, ni de la bronquitis. No me quejo de picor en los ojos, ni del tímpano, ni del entumecimiento en el brazo. No me quejo del riñón. No me quejo de la sequedad de boca. No me quejo del mareo. No me quejo de la falta de apetito. No me quejo de los dolores que tengo en las articulaciones. No me quejo de las preocupaciones. No me quejo del insomnio. No me quejo del escozor en las vías urinarias. No me quejo de la retención de orina. No me quejo del cansancio. Me quejo de todo eso. No me he quejado a los vecinos. No me de quejado a mi hijo. No me he quejado a los transeúntes. No me he quejado al cajero encargado de las pensiones, ni al que vende habas debajo de la casa, ni al portero. No me he quejado al cobrador del autobús. No me he quejado al cartero. No me he quejado al que me preguntó o al que no me ha preguntado. He venido a quejarme al doctor. Quiero hacerme un chequeo: análisis y radiografías, un reconocimiento con el estetoscopio, un reconocimiento con el espéculo, una cardiología, un cultivo...; todo lo que haga falta. Si se me pregunta por qué no he venido mucho antes, por qué no vine cuando sentí esos síntomas, contestaré diciendo que no me lo podía permitir y tenía la mente puesta en otras cosas. ¿Qué puedo decir? Cada vez que conseguía un ascenso, el niño crecía, había que hacer hincapié en las clases particulares, el precio de la visita era más y más caro, y yo me quedaba con las manos vacías postergando el asunto para el próximo mes, para el próximo año, para cuando el niño consiguiera su título, para cuando tuviera un contrato laboral en el extranjero, y así hasta que Dios le dio fortuna. Se colocó fuera y el niño no ha escatimado. Me ha mandado el dinero, y he venido. Llevo esperando 
al doctor un mes, dos meses, un año, dos años. ¡Dios nos dé larga vida, pues tenemos para rato con el enfermo que va antes de mí! Lleva cuatro meses dentro diciendo «iay!». El enfermo anterior estuvo seis meses y cinco días dentro y salió sano. El que iba antes de él sólo estuvo una semana, un día y una hora y murió dentro antes de que usted, señorita, consiguiera este trabajo. Y yo, entretanto, estoy esperando. El doctor hace un reconocimiento minucioso y debe saber el origen de la enfermedad antes de pronunciarse. Y aquí estoy yo. Tanto si me pregunta como si no me pregunta, me quejaré. Sí, me quejaré con todos los tonos de voz, empleando todas las escalas musicales; desde lo más profundo, desde el corazón, desde el pecho, desde el vientre, desde la cabeza diré: «jay!», «iay!». Cuando llegue el momento, me quejaré. Delante de mí había diez números. He vuelto, y ahora es mi turno, y cuando me toque diré «iay!».

LOS ENFERMOS: ¡Ay!

¡Ay!

¡Ay!

(Se abre la puerta del Médico. Sale el enfermo tosiendo y se cae al suelo. Los dos enfermeros lo llevan afuera.)

El Médico: Otro.

(Los enfermos que acuden se pelean debajo del rótulo del Médico.)

EL INDIVIDUO: ¡Ay! ¿Qué puedo hacer con este tropel? ¡Oigan! Es mi turno.

(Se paraliza la escena en torno al Individuo. Después se va desvaneciendo poco a poco para convertirse en una sala de exámenes.)

Pero la pregunta no es sobre eso. No es «¿qué edad tienes?» ni «¿hay en tu familia una enfermedad hereditaria?» ni «¿de qué me quejo?» ni «¿dónde vives?». Ninguna de ésas son las preguntas. Las preguntas son más difíciles. Y el examen es a las tres, que es la hora que yo tengo.

\section{LAS TRES}

(En el pabellón de exámenes. A su alrededor hay otros individuos examinándose.)

EL INDIVIDUO: La pregunta no aparece por escrito, pero no se permite preguntar al examinador. No se permite preguntar al compañero. No se permite preguntar a derecha ni a izquierda. La hoja de las preguntas está en blanco, al igual que la hoja de las respuestas. Éste es el examen. Tú debes escribir la pregunta y la respuesta. Y para saber la respuesta debes conocer la pregunta. ¿Cuál es la pregunta? Primero ponemos el signo de interrogación y después pensamos la pregunta. Al venir esta mañana uno me preguntó: «¿Qué hora es?» Esta pregunta es sobre el momento. Es 
una pregunta sobre el tiempo. Si pongo esa pregunta, no sabré responderla. La pregunta más difícil es la que gira en torno al tiempo. Otro en el autobús me preguntó: ¿Cómo van las cosas? Es una pregunta económica. Y yo no entiendo de economía. Si pongo esa pregunta, no sabré responderla. No vale la pregunta. « ¿Tu hijo está contento en el extranjero?» me preguntó uno al saludarme en la calle. Es una pregunta posible. ¿La pongo? Pero la respuesta es también difícil, es una pregunta imposible, porque la pregunta es sobre la política exterior y las relaciones internacionales, y yo no entiendo de política, no sé dónde está el extranjero. Y si lo supiera y contestara, seguro que me equivocaría. La pregunta fácil es la que tiene respuesta. Pero la pregunta que no tiene respuesta es difícil y toda posible respuesta sobre la misma equivale a cero escrito en mayúscula. «¿Dónde te metes, hombre?» Me encontré con uno que no conozco o que quizá conociera de antes y no caía quien era. Me lo encontré en la puerta de casa y me preguntó: «¿Dónde te metes, hombre?». Es una pregunta difícil, porque cae dentro de la filosofía del «¿dónde?». «¿Dónde estamos?, ¿por qué estamos?, ¿de dónde venimos?, ¿a dónde vamos?, ¿qué esperamos?», todas ellas son cuestiones filosóficas. Y yo he olvidado a Aristóteles, Platón, Avicena, Averroes. La biblioteca que hay en casa se ha destruido. Los documentos que contiene son numerosos, pero las letras se han borrado hace tiempo. Aquí estoy buscando la pregunta. Hay una única respuesta que aún recuerdo. Puedo formularle una pregunta. La respuesta es «pienso, luego existo». ¿Cuál es la pregunta? Hasta eso no sirve, porque yo no pienso en este momento, es decir, no existo en este momento. Desapareces del examen sin excusa. No estás presente, no estás aquí. Estás ausente. Ausencia del examen. No tienes excusa. La hoja está en blanco y alguien que no conozco escribirá en ella «suspenso». En mayúscula, en letra de molde o en cursiva el resultado es el mismo. Y si pregunto, nadie me contestará. Son muchas las cartas que he enviado a mi hijo al extranjero sin obtener respuesta. Y tengo miedo de mí mismo. Es como si uno fuera mudo y quisiera hablar. Es como si uno fuera sordo y le hablaran.

(La escena del examen ha ido desvaneciéndose paulatinamente.)

Es como si tuviera miedo del tiempo. El tiempo pasa volando, ya son las cuatro. El tiempo se me va de las manos.

\section{LAS CUATRO}

(Paulatinamente va apareciendo la siguiente escena: en la parte posterior hay una jaula con un Gorila salvaje y que está constantemente moviéndose de aquí para allá; los personajes están inmóviles, pese a su apariencia de estar paseando por un zoológico; hay una mesa de escritorio en la que está un Amanuense. El Individuo le dicta una carta mientras que lo mira fijamente.) 
EL INDIVIDUO: No me preguntes por qué he recurrido a ti para escribir una carta a mi hijo. ¿Es que no sé escribir? Claro que sé, pero le he enviado cientos de cartas a las que no ha respondido. Me dije: «Voy a cambiar de letra. Quizá sea precisamente mi letra lo que él no sabe leer o lo que no sabe leer el cartero». Escribe: «Querido hijo: Estoy bien».

El AMANUENSE: (Sin dejar de mirar al Individuo.) Estoy bien y todos por aquí se encuentran bien y te envían muchos saludos.

EL INDIVIDUO: ¡Qué cosas dices! ¿Pero qué estás diciendo? ¿Quiénes son los que están bien y le envían muchos saludos?

EL AMANUENSE: Son formalidades.

EL INDIVIDUO: La única formalidad es que escribas tal cual lo que te dicto.

El AMANUENSE: Tú no conoces las pautas de escritura.

EL INDIVIDUO: Pero me conozco a mí mismo, conozco a mi padre y conozco a mi hijo.

EL AMANUENSE: Una expresión como ésta — «todos por aquí se encuentran bien y te envían muchos saludos» - reconforta el espíritu del chico en el exilio. Es como «la patria te añora», «eres el embajador de tu país y prototipo del joven virtuoso en el extranjero» 0 «te envío tus giros por medio del Banco Central que impulsa la patria», «con el amor de Egipto...», etc. Es la elocuencia de nuestro tiempo.

EL INDIVIDUO: ¡Palabras, palabras y más palabras! Has ido demasiado lejos. Y si mi letra era ilegible, aunque tú escribas con letra magistral, nadie te va a entender.

El AMANUENSE: Te ruego que no chilles porque los animales se alteran con el vocerío.

EL INDIVIDUO: Soy yo el que te paga para que escribas. Escribe lo que te dicto, palabra por palabra y letra por letra.

El AMANUENSE: ¡Comprende lo que te estoy diciendo, zoquete! Conforme más chilles, más se alteran los animales.

EL INDIVIDUO: ¡Se acabó! Me niego a que escribas nada. ¡Dame el papel y la pluma!

El AMANUENSE: ¡Pero hombre, el papel es mío y la pluma es mi medio de vida!

EL INDIVIDUO: Mira lo que hago con el papel (lo hace pedazos) y con la pluma (la rompe).

El AmANUENSE: (Sujetándolo.) ¡Baja la voz! ¡Maldita sea tu estampa!

(El Gorila, que se ha ido enfureciendo poco a poco, coge y abre los barrotes de la jaula chillando. Todos salen espantados al ver al Gorila entre ellos. Después vuelven y se sitúan en torno al Individuo ante la señal de una parada de autobús en la que hay escritos distintos números. Los personajes están en ademán de esperar el autobús.) 
(En la parada del autobús. Los autobuses pasan de largo, como podemos observar por los giros que se producen en la cabeza de los personajes.)

EL INDIVIDUO: Autobús 14, no para. Autobús 14 con señal de ruta alternativa, no para. Autobús 29, no para. Autobús en dirección a Gamra, no para. Llevo cuatro días de pie clavado como esta gente que está aquí, y los autobuses no paran. ¿Qué puedo hacer? Es una parada y tiene escrito «parada obligatoria». Está visto que la obligatoriedad no es para el autobús, sino para la gente. La gente está inmóvil, pero el autobús no para. Una vez paró por sorpresa, y me subí y no volvió a detenerse. Y ahí te encuentras dando vueltas como un pato mareado en el autobús por todo El Cairo ${ }^{6}$ : de Shobra a Raud el-Fárag; subió por el-Abbasía y bajó por el-Azhar y el-Átaba, saliendo pitando hacia el-Giza y volviendo atravesando Faysal, ed-Doi, Zamalek, Bulá y así hasta el-Warrá, entrando a Shobra el-Jema para llegar de allí a Ahmed Hilmi. Dieciocho horas y ¡cataplum! Y ¿qué explicación dieron? Pues que se había parado porque cuatro ruedas se habían pinchado y el conductor había alcanzado la edad de la jubilación. Los pasajeros, entre ellos yo, nos bajamos y echamos a correr por las calles pidiendo socorro, mientras que la gente igualmente corría detrás de nosotros también pidiendo socorro, sin que ninguno pudiera dar alcance al otro. $Y$, para colmo, la parada es obligatoria y los autobuses no paran. Pero yo voy a hacer que se paren. ¡Ahí viene! ¡Estoy aquí parado! ¡Detente! ¡Tienes que parar!

(Se desploma. Silbato. Sirena de ambulancia. Lo trasladan en una camilla con ruedas.)

\section{LAS SEIS}

(Rótulo de quirófano. Los Jóvenes empujan con rapidez la camilla hacia el interior de la sala y el Individuo corre detrás. Él es en cierto momento la persona que yace en la camilla. Se cierra la puerta en sus narices y se queda inquieto caminando de un lado a otro.)

EL INDIVIDUO: Una hora en el quirófano. Dos, tres horas. No sé. No puedo percibir el paso del tiempo porque estoy anestesiado.

(Aparece el Médico.)

Tranquilíceme, doctor. ¿Ha salido bien?

El MÉDICO: ¿Es pariente suyo?

EL INDIVIDUO: No.

\footnotetext{
${ }^{6}$ Enumera puntos muy conocidos de la capital y que están alejados entre sí.
} 
El MÉDICO: ¿Su vecino?

EL INDIVIDUO: No.

EL MÉDICO: ¿Un amigo?

EL INDIVIDUO: No.

EL MÉDICO: ¿Qué relación tiene entonces con él?

EL INDIVIDUO: Soy él. Yo soy el herido que está dentro, el que está bajo el efecto de la anestesia, al que acaba de hacer la operación. Soy el que está preguntando por sí mismo, el que trata de tranquilizarse a sí mismo. No tengo a nadie más que pregunte por mí. He venido a preguntarle. Aquí me tiene.

EL MÉDICO: Seas tú o no, no es asunto mío. Si tienes alguna queja o cualquier otra cosa que alegar, la presentas de modo oficial. El hospital cumplió con su deber. ¡No nos vengáis con vuestros problemas! La operación ha sido todo un éxito. ¿De qué vienes a quejarte?

EL INDIVIDUO: No me estoy quejando. No me gusta quejarme, pero estando dentro bajo el efecto de la anestesia he sentido como si estuviera ausente, he visto espectros a mi alrededor. Y me gustaría entrar a echarme un vistazo y a decirme algo que me dé aliento y me tranquilice. Le ruego que me permita hacerme una visita, echarme un vistazo, tranquilizarme y consolarme interiormente con unas palabras.

El MÉDiCO: ... ¿Cómo vas a entrar si ya estás dentro? ¿Y cómo has salido y estás al mismo tiempo dentro y fuera? No tengo tiempo de considerar el asunto y, además, no cae dentro de mis competencias. ¡Un teléfono, Zakía! (La Enfermera le da el teléfono. Marca el número.) ¡Oiga, doctora! Envíeme ahora mismo dos enfermeros de la sección de neurología con la camisa de fuerza. Los necesito ahora mismo. ¡Inmediatamente! Los necesito.

(Entran los Enfermeros y le colocan al Médico la camisa mientras que éste opone resistencia.)

El Médico: No es a mí. Oye, ¿y a qué viene tanta prisa en ejecutar esta orden como es debido?

\section{LAS SIETE}

EL INDIVIDUO: ¡Caramba! Me he retrasado y ¡vaya calor que hace! Ya son las siete.

(La puerta de la vivienda está en uno de los lados del escenario. En la parte exterior hay una mesa de café en la que están sentados el Rico y el Policía. En el interior hay una ventana, una percha y dos sillas. El Individuo abre la puerta empleando la llave y entra. Comienza a quitarse la ropa, la peluca y el maquillaje y resulta ser un 
muchacho de unos veinte años. Se pone una camisa de colorines. Cierra la ventana y la habitación queda a oscuras. Echa la cortina y en la misma hay un dibujo de una playa. Se ve el mar y el cielo. Coloca las dos sillas y sobre las mismas abre una sombrilla de playa. Entran los personajes, en grupos y unos detrás de otros, con sillas de playa. Música de baile ligera.)

LA ENFERMERA: Alejandría está hasta los topes. Hemos conseguido un sitio en Abu Talat.

EL MÉDICO: ¡Uf! ¡Esto está que arde!

LA BAILARINA: Las profesiones liberales son mejores que cualquier puesto de trabajo.

EL SEMEJANTE: Hace falta un gran capital.

EL JOVEN 1: ¿Y crees que esta jugada no se va a descubrir? ¡Menuda nos va a caer!

EL JOVEN 2: El millón, cuando le pongamos las manos encima, será la mejor cortina y tapadera.

El SEMEJANTE: Estoy con él.

El INDIVIDUO: ¡Y a mí qué! (Saca su clarinete y se pone a tocar. Actuación de baile.)

(Llaman a la puerta. Vuelven a llamar, dejan lo que estaban haciendo, salen en escapada por aquí y por allá, mientras el Individuo nervioso recoge las sillas y las sombrillas rápidamente y se coloca la indumentaria y el maquillaje del anciano a toda prisa.)

(En la parte exterior de la vivienda está el Portero tocando y le acompaña el Cartero. El Rico y el Policía están en el café que hay junto a la puerta.)

EL RICO: He visto hace poco a su padre entrando.

EL PORTERO: Te estoy diciendo que su padre murió hace dos años y que yo mismo lo llevé a hombros.

EL Rico: ¡Alabado sea Dios! Lo he visto con mis propios ojos. ¡Qué cosas dices!

El CARTERO: ¿Qué podemos hacer? Esto es una carta certificada.

El PORTERO: Estaba esperando esa carta desde hace tiempo y me tenía sobre aviso. Debe ser la carta de la oficina gubernamental de empleo. En ese caso, ya está solucionado lo del trabajo, y cogeremos la gratificación que estábamos esperando.

El Policía: Te está diciendo que su padre está dentro. ¡Toca otra vez!

El PORTERO: ¡Dejaros de locuras! A ese lo acompañé en su funeral yo mismo hace tiempo.

EL CARTERO: ¡Al grano! Firma por él.

EL PORTERO: Te firmo, y echas la carta por debajo de la puerta. 
El CARTERO: Vale.

(Así lo hacen.)

EL INDIVIDUO: (Coge la carta con cuidado y la abre.) Es el billete del avión. Y a las nueve cojo el vuelo que tengo reservado.

\section{LAS OCHO}

(El Individuo y su Semejante se encuentran frente a frente. Todos los movimientos que realiza el Individuo son efectuados por el Semejante al revés.)

EL INDIVIDUO: ¡Dios!

EL SEMEJANTE: ¡Dios!

EL INDIVIDUO: Es extraño.

EL SEMEJANTE: Extraño es.

EL INDIVIDUO: Yo te he visto antes.

EL SEMEJANTE: Antes visto he te yo.

EL INDIVIDUO: Me dije: «quizá sea una ilusión óptica».

EL SEMEJANTE: «Óptica ilusión una sea quizá», me dije.

EL INDIVIDUO: ¿Quién eres?

EL SEMEJANTE: ¿Eres quién?

EL INDIVIDUO: No sé quién eres ni de dónde me puede venir tu imagen. Te veo entre ese tropel de gente y te veo en mi soledad. ¿Qué quieres de mí? ¿por qué me persigues? ¿por qué vistes igual que yo y te veo constantemente ante mí? Te estoy hablando. ¡Háblame!

El SEMEJANTE: ¡Háblame! Hablando estoy te. ¿Mí ante constantemente veo te y yo que igual vistes qué por? ¿persigues me qué por? ¿mí de quieres qué? Soledad mi en veo te y gente de tropel ese entre veo te. Imagen tu venir puede me dónde de ni eres quién sé no.

EL INDIVIDUO: ¡Estamos buenos! Yo trato de ordenar mis ideas en un discurso tal y como escribo, de derecha a izquierda, y tú lo haces de forma idéntica a mí, pero de izquierda a derecha. Es como si estuviera ante un espejo. Pero, ¿cómo va a reflejar el espejo mis palabras? ¡Dime!

El SEMEJANTE: ¡Dime! ¿Palabras mis espejo el reflejar a va cómo?, pero. Espejo un ante estuviera si como es. Derecha a izquierda de pero, mí a idéntica forma de haces lo tú, 
izquierda a derecha de, escribo como y tal discurso un en ideas mis ordenar de trato yo. ¡Buenos estamos!

EL INDIVIDUO: Es como si fuera yo mismo, pero al revés. Bien, ¿y si yo fuera el que está al revés y él el que está al derecho? Entonces yo sería la reproducción y él el original. Tengo miedo y necesito pedir ayuda, pero si acudiera a alguien diría que estoy loco.

El SEMEJANTE: ¡Me estoy llamando a mí mismo!

EL INDIVIDUO: A mí mismo me estoy llamando yo, supongo que quieres decir.

El SEMEJANTE: Decir quieres que supongo, yo llamando estoy me mismo mí a.

EL INDIVIDUO: ¡Que alguien me ayude!

El SEMEJANTE: ¡Ayude me alguien que!

(Atabales. Salen huyendo de forma opuesta y entran en escena en su lugar los dos Jóvenes con la vestimenta apropiada para la celebración de un ceremonial de exorcismo rodeados de los otros con adufes del colorido del arco iris. Los dos Jóvenes danzan de forma semejante haciendo movimientos ritmicos en direcciones opuestas.)

EL INDIVIDUO: (Entrando.) ¿Qué es lo que me ha retrasado siendo ya las nueve?

\section{LAS NUEVE}

(La escena tiene lugar en el aeropuerto. El Individuo está sentado ante una azafata de tierra. El aeropuerto da la impresión de estar de bote en bote, pero los personajes están inmóviles. No hay movimiento alguno en el aeropuerto.)

EL INDIVIDUO: Ya te he dicho que debe de haber un error. Mi hijo trabaja en el extranjero. Me ha enviado un billete desde allí. ¿Cómo me dices que este billete que está a mi nombre es un billete de tren para Luxor si yo no tengo a nadie en Luxor y mi hijo está en el extranjero? Jamás he vuelto a Luxor desde que vine al mundo. Después de que yo naciera en Luxor nos vinimos inmediatamente a El Cairo. Y mi hijo, cuando consiguió el título, cogió y se fue a trabajar al extranjero. Me ha enviado un billete para que vaya a verlo. Puede que yo haya cometido también un error al venir aquí. Éste es el aeropuerto, pero me estás diciendo que todos los aviones están paralizados en el aire, los viajeros están paralizados sin moverse y tú no quieres comprenderme. Me dirijo al extranjero y tú quieres mandarme a Luxor. Voy a ver a mi hijo y tú quieres que vaya a ver a mis antepasados. ¿Vamos hacia adelante o hacia atrás? Pero, además, todo está paralizado. Tengo un billete, pero no puedo comprender lo que pasa. Si pudieras darme una explicación, me tranquilizarías. Contesta a lo que te pregunte. Y cuando te responda, vuelve a preguntarme. Mi hijo me está esperando y yo no puedo moverme. ¿Quieres que me ponga a gritar y llame la atención de la 
gente? Voy a ponerme a gritar y a decir: «¡Oye, echadme una mano!». Nadie se moverá.

(Se le acerca un Policía y todo el mundo se pone a moverse. Le pone la mano en el hombro y la escena se paraliza. Se apaga la luz paulatinamente mientras que se escucha un aviso a través del micrófono.)

El Micrófono: Última llamada para los pasajeros del avión a Luxor. Diríjanse a la sala de embarque inmediatamente.

\section{LAS DIEZ}

(En la estación de ferrocarril. Los personajes son un vendedor de periódicos y viajeros, que están inmóviles. $Y$ en primer plano hay un vagón de tren vacío.)

EL INDIVIDUO: ¿Es éste el tren de las diez a Luxor? Tiene que ser éste. Mi vagón debe ser éste que está preparado, y resulta que me he olvidado el equipaje. Cuando se ponen a hacer cualquier construcción, colocan la primera piedra, y en esa primera piedra ponen los periódicos publicados el día en que se fijó la piedra. (Coge los periódicos, hace un cucurucho con un de ellos y mete lo que quedará para la posteridad en el cucurucho.) Un poco de dinero en metálico o en billete (lo pone), la página de un calendario en la que esté escrita la fecha de ese día (quita una hoja del almanaque que tiene el vendedor de periódicos y la pone) y una copia del permiso de construcción de la obra con los sellos del Estado. Aquí está el documento de identidad. Ponemos también un puñado de tierra del país, un poco de algodón del que exportamos -pero no ponemos trigo, porque lo importamos-, un acta del Consejo del Pueblo de ese día, La Gaceta Egipcia ${ }^{7}$, la última sentencia del Tribunal de Casación, un libro para aprender a leer de alumnos de primaria, un ejemplar de una tarjeta de invitación para la colocación de la primera piedra, un trozo de hierro producido por la fábrica de acero en símbolo de la industria, una botella llena de agua del Nilo, unos pocos cojinetes de bolas producidos por la industria autovomilística, anuncios publicitarios elaborados a mano de las películas y de las obras de teatro que se exhiben en su día y el último libro publicado por la imprenta del Estado. Encima de todo esto se pone una piedra de granito de Asuán alrededor de la cual se colocan las provisiones, de modo que dentro de mil años, si vinieran los arqueólogos a hacer excavaciones en el lugar, sabrían de cuándo data esta construcción, el porqué y el objetivo de la misma y qué tipo de vida existía entonces. Me voy a llevar todo esto a Luxor en lugar del equipaje. Y, siguiendo las indicaciones del billete que tengo y estando sonando la campana de salida, tomaré el tren. (Apenas se sube en el recinto

\footnotetext{
${ }^{7}$ Se trata del periódico árabe más antiguo, al-Waqāa $i^{c}$ al-Mișriyya, fundado el 3 de diciembre de 1828, bajo los auspicios de Muhammad ' $\mathrm{Ali}$, como periódico oficial de Egipto con el objetivo de difundir noticias de Estado y otros asuntos de interés para el gobierno.
} 
descubierto, se lanzan sobre él los cestos, las maletas y los diez pasajeros.) ¡Pero oye! ¿Qué es esto? (Y desaparece debajo de los bultos.)

\section{LAS ONCE}

(Silbato del tren. El humo que desprende hace desaparecer a todos a excepción del Individuo, que está a la intemperie. Lleva el cucurucho y viste con la ropa del muchacho.)

EL INDIVIDUO: Son las once, y no sé qué camino debo tomar. ¡Buen hombre!

(Aparece el Policía.)

¿Dónde es la boda?

El Policía: No sé.

EL INDIVIDUO: ¿Dónde está Kafr Sad?

El Policía: No sé.

EL INDIVIDUO: ¿A dónde conduce este camino?

El Policía: No sé.

EL INDIVIDUO: ¿De dónde vienes?

El Policía: No sé.

EL INDIVIDUO: ¿Cómo te llamas?

El Policía: No sé.

EL INDIVIDUO: ¿En qué punto está tu puesto de trabajo?

El Policía: No sé.

EL INDIVIDUO: ¿Y dónde ha ocurrido el crimen?

El Policía: No sé.

EL INDIVIDUO: ¿De qué crimen se trata?

El Policía: No sé.

EL INDIVIDUO: ¡Ay! ¿Y cómo puedo reconocer el pueblo?

EL POLICÍA: No sé.

EL INDIVIDUO: ¿Qué es esa luz que hay allí?

El Policía: No sé. 
EL INDIVIDUO: ¿Qué es esa sombra que hay allí?

El Policía: No sé.

EL INDIVIDUO: Llevas un silbato. ¡Anda, silba a ver si alguien acude en nuestra ayuda!

El Policía: No sé.

EL INDIVIDUO: Deténme y llévame a la comisaría.

El Policía: ¿Acusado de qué?

EL INDIVIDUO: De vagabundear.

El Policía: ¿Tienes carné de identidad?

EL INDIVIDUO: No sé.

UnA Voz: (Desde fuera.) Ha llegado el novio. ¡Aquí está!

\section{LAS DOCE}

EL INDIVIDUO: ¿Son ya las doce?

(Entran los personajes con las sillas y en las manos llevan cucuruchos. Se sientan formando una fila ordenada a excepción de los dos Jóvenes, que rodean al novio.)

EL JOVEN 1: ¡Ésta es tu noche, novio!

EL JOVEN 2: ¿Por qué te has retrasado, si la novia te está esperando?

EL INDIVIDUO: Me he perdido, y antes de eso me había olvidado y antes de olvidarme no sabía... a qué hora era la cita. Para nosotros, los humanos, siempre los sueños andan por un lado y la realidad por otro. Si el hombre camina por el sendero de los sueños, no puede conducirlo a este mundo; y si camina con los pies en el suelo, por más que se prolongue su camino, no puede alcanzar sus sueños. Pero lo más cruel que puede pasarle es la soledad... el aislamiento, la ruptura con todo lo que le rodea. Por eso, el que mantiene su comunicación con el mundo real está en mejor situación que el que rompe sus relaciones con este mundo. Pero, ¿qué pueden hacer los seres humanos respecto al abismo existente entre su vida cotidiana y sus sueños, entre su trayectoria y su objetivo, entre el lenguaje y la palabra, la escisión de la memoria, la diferencia entre el conocimiento y la comprensión, entre el ingenio y los intereses, entre el padre y su hijo...?

EL JOVEN 1: (Lo interrumpe muerto de risa.) Me has partido el corazón.

EL Joven 2: (Muerto de risa.) Me rasgo las vestiduras. El estrado preparado para los novios está ante ti, novio. 
EL INDIVIDUO: Y yo lo que tengo es ganas de desaparecer. Desearía que esto no hubiera sucedido.

EL JOVEn 2: ¡Quietos para la foto!

(Prepara la cámara y corre a sentarse con los otros en fila inmóvil y recto. Lapso de silencio. Entra el Portero vestido de Intérprete y el Rico.)

EL INDIVIDUO: ¿Son ya las doce?

(Vuelven a entrar los personajes con las sillas y se sientan formando una fila ordenada. La Bailarina danza. Uno de los jóvenes empuja al Individuo.)

El Joven 1: ¡A tu asiento, novio!

EL Joven 2: ¡Una foto, una foto! ¡Quieto!

(Coloca la cámara y se sienta, quedando la escena inmóvil. La luz va intensificándose gradualmente. El novio, habiéndose quitado la ropa del anciano, ha vuelto a ser un muchacho. Junto a él está inmóvil la Enfermera, vestida de novia. Entran de nuevo el Portero y el Rico.)

EL RICO: ¿Llevan mucho tiempo en esta situación?

EL PORTERO: ¿Las imágenes que hay allí en el templo? Sí, mucho.

EL Rico: ¿Y qué esperan?

EL PORTERO: Que venga el encargado de las ceremonias nupciales.

EL RICO: ¿Y cuándo vendrá ese encargado?

El Portero: No tengo ni idea. Pero, cuando vaya a venir el encargado de ceremonias, habrá una señal; y cuando la veas, es que está al caer.

EL RicO: ¿Y cuál es la señal?

EL PORTERO: Aparecerá de repente una nube y se pondrá a llover.

EL Rico: ¡Pero si jamás ha llovido en Luxor!

EL PORTERO: Lloverá.

(Los actores se ponen de pie. Inmovilidad. Elevan las pancartas como al principio. El mismo baile expresionista que tuvo lugar al comienzo con los signos.) 